\title{
Stop the escalators: using the built environment to increase usual daily activity
}

\author{
This article was published in the following Dove Press journal: \\ Pragmatic and Observational Research \\ 18 September 2010 \\ Number of times this article has been viewed
}

\section{John MWestfall \\ Doug H Fernald}

Department of Family Medicine, University of Colorado Denver,

Aurora, CO, USA
Correspondence: John MWestfall Department of Family Medicine, University of Colorado Denver, Mail Stop F706, AOI, I 263 I East

17th Ave, Aurora, CO 80045, USA

Tel +l 303724 97/2

Email jack.westfall@ucdenver.edu
Background: Obesity is an epidemic in the United States. Two-thirds of the population is overweight and does not get enough exercise. Eastern cities are full of escalators that transport obese Americans to and from the subway. Walking stairs is a moderate activity requiring 3-6 metabolic equivalent tasks (METS) and burning 3.5-7 kcal/min. We determined the caloric expenditure and potential weight change of the population of one eastern city if all the subway riders walked the stairs rather than ride the escalators.

Methods: There are 5,000,000 daily journeys made on the New York City Subway. Subway entrances include a stairway or escalator of approximately 25 steps. Each step up requires $0.11-0.15 \mathrm{kcals}$; each step down requires $0.05 \mathrm{kcals}$. To lose one pound requires burning 3500 kcals. We assumed each rider made a round trip so about 2.5 million individual people ride the subway each day.

Results: By walking stairs rather than riding escalators, the riders of the New York Subway would lose more than 2.6 million pounds per year.

Discussion: The average subway rider would lose about one pound per year. While this may sound insignificant, in one decade the average subway rider would lose 10 pounds, effectively reversing the trend in the United States of gaining 10 pounds per decade. This conservative estimate of the number of stairs ascended daily means that subway riders might lose even more weight. We believe that this novel approach might lead to other public and private efforts to increase physical activity such as elevators that only stop on even numbered floors, making stairwells more attractive and well lit, and stopping moving sidewalks. The built environment may support small, incremental changes in usual daily physical activity that can have significant impact on populations and individuals.

Keywords: obesity, escalators, physical activity, built environment

\section{Background}

Obesity is an epidemic in the United States. Increasing steadily over the past quarter century, $32 \%-35 \%$ of the US population are now obese, and two-thirds are overweight. ${ }^{1}$ The prevalence of obesity in young people has more than doubled. ${ }^{2}$ Obesity rates are higher among non-Hispanic Blacks and Mexican Americans. ${ }^{2}$ Additionally, over half of the US population does not get enough exercise. ${ }^{3}$ Physical activity has been shown to have a positive impact on health and longevity. ${ }^{4}$ Diez Roux et $\mathrm{al}^{5}$ and Cohen et $\mathrm{al}^{6}$ found that the availability of common recreational spaces such as parks and sports facilities were related to increased activity. The built environment can incorporate "usual daily activities" as a potential source for increased exercise and energy expenditure.

While traveling on the East Coast we were struck by the number of escalators that transport overweight Americans up and down from the street level to the subway 
system. Walking up and down stairs is reported as a moderate activity requiring 3-6 METS and burning 3.5-7 kcal/min. ${ }^{7}$ We determined to measure the impact of stopping the subway escalators on caloric expenditure and weight of the population of one eastern metropolitan area.

\section{Methods}

We obtained the number of daily subway riders in New York City. There are 5,000,000 riders on the New York City Transit Subway system each day. ${ }^{8}$ (Approximately 1.5 billion per year.) Each rider must enter and exit the subway via the stairs or escalator. There are 169 escalators on the NYC subway system. ${ }^{9}$ Based on our observations, we estimated that each entrance includes a stairway escalator of approximately 25 steps, with many escalators moving 50-75 steps. Therefore each rider descends and ascends approximately 25 steps. Each step up requires $0.11-0.15$ kcals, and each step down requires 0.05 kcals. ${ }^{10,11}$ To lose one pound requires burning 3500 kcals. ${ }^{12}$ We calculated the number of calories burned and the subsequent pounds lost if the New York City Subway stopped their escalators. We assumed each rider weighed the standard $70 \mathrm{~kg} .{ }^{13}$ And we assumed each rider made a round trip ( 2 entrances and 2 exits) so about 2-2.5 million individual people ride the subway each day.

\section{Results}

By walking the stairs rather than riding the escalators, the riders of the New York City Transit Subway would lose more than 2.6 million pounds per year.

$$
\begin{aligned}
& (5,000,000 \mathrm{riders} \times 25 \text { stairs up } \\
& \times 0.15 \mathrm{kcal} / \text { stair })+(5,000,000 \text { riders } \\
& \times 25 \text { stairs down } \times 0.05 \mathrm{kcal} / \text { stair }) \\
& =25,000,000 \mathrm{kcal} / \text { day } \div 3500 \mathrm{kcal} \\
& =7142 \mathrm{lb} / \text { day } \times 365 \text { days } \\
& =2,607,142 \text { pounds per year. }
\end{aligned}
$$

The population of subway rides would lose over 2.6 million pounds per year. The subway includes approximately 2-2.5 million riders so each individual rider will lose approximately 1 pound each year.

\section{Discussion}

The average subway rider would lose about one pound per year. While this may sound insignificant, in one decade the average subway rider would lose 10 pounds, effectively reversing the trend in the United States of gaining 10 pounds per decade. This conservative estimate of the number of stairs ascended daily and the conservative estimate of caloric cost per step means that it is likely that subway riders would lose even more weight. Other cities with subways may enjoy similar results. The Washington DC subway system includes 86 subway stations with 588 escalators. ${ }^{14}$

We believe that this novel approach might lead to other public and private efforts to increase physical activity such as elevators that only stop on even numbered floors, making stairwells more attractive and well lit, and stopping moving sidewalks. While it may not be feasible to stop the escalators in New York City, this short analysis points out how even small changes in the built environment may change usual daily activity leading to increased exercise, and improved fitness. The built environment provides important access to physical activity and recreational facilities and may be one component of our national efforts to positively impact population health with respect to increasing physical activity. Reichert et al found that lack of money and lack of time were major barriers to physical activity. ${ }^{15}$ Because obesity is particularly prevalent in low-income communities the local built environment may be an important component of programs to increase physical activity among low-income communities. ${ }^{16}$

Our calculations include several limitations. Not all subway stations include an escalator and not all riders use the escalator. Many riders may have physical limitations that require use of an escalator or elevator. However, our intent is not to precisely measure the energy expenditure related to walking stairs. Rather, our intent is to point out the impact the built environment may have on our usual daily activities.

It is important to consider the built environment to support increasing usual daily activities as a target for the increasing physical activity. In this study we show that even small, incremental changes in physical activity may have significant impact on populations and individuals.

\section{Disclosure}

No conflicts of interest were declared in relation to this paper.

\section{References}

1. Flegal KM, Carroll MD, Ogden CL, Curtin LR. Prevalence and trends in obesity among US adults, 1999-2008. JAMA. 2010;303(3):235-241.

2. Ogden C, Carroll M. Prevalence of obesity among children and adolescents: United States, trends 1963-1965 through 2007-2008 [online]. Accessed 2010, Aug 25. Available from: http://www.cdc.gov/ nchs/data/hestat/obesity_child_07_08/obesity_child_07_08.pdf

3 Centres for Disease Control and Prevention (CDC). Physical activity for everyone [online]. Accessed 2010, Aug 25. Available from: http://www. cdc.gov/nccdphp/dnpa/physical/importance/index.htm

4. Centres for Disease Control and Prevention (CDC). The link between physical activity and morbidity and mortality [online]. Accessed 2010, Aug 25. Available from: http://www.cdc.gov/nccdphp/sgr/mm.htm 
5. Diez Roux AV, Evenson KR, McGinn AP, et al. Availability of recreational resources and physical activity in adults. Am J Public Health. 2007;(3):493-499.

6. Cohen DA, McKenzie TL, Sehgal A, Williamson S, Golinelli D, Lurie N. Contribution of public parks to physical activity. Am J Public Health. 2007;(3):509-514.

7. US Department of Health and Human Services, Public Health Service, $\mathrm{CDC}$, et al. General physical activities defined by level of intensity [online]. Accessed Aug 25, 2010. Available from: http://www.cdc.gov/ nccdphp/dnpa/physical/pdf/PA_Intensity_table_2_1.pdf

8. Metropolitan Transportation Authority. Subway and bus ridership [online]. Accessed Aug 25, 2010. Available from: http://www.mta. info/nyct/facts/ridership/index.htm

9. NYC Subway News. NY City subway escalators get an energy-efficient facelift [online]. Accessed Aug 25, 2010. Available from: http://www. nycsubwaynews.com/mta/ny-city-subway-escalators-get-an-energyefficient-facelift/

10. Teh KC, AzizAR. Heart rate, oxygen uptake, and energy cost of ascending and descending the stairs. Med Sci Sports Exercise. 2002;34(4): 695-699.
11. Bassett DR, Vachon JA, Kirkland AO, Howley ET, Duncan GE, Johnson KR. Energy cost of stair climbing and descending on the college alumnus questionnaire. Med Sci Sports Exercise. 1997;29(9): 1250-1254.

12. Lowfat Lifestyle [online]. Accessed 2010, Aug 25. Available from: http://www.lowfatlifestyle.com/calories.htm

13. Elert G, editor. Mass of an adult [online]. Accessed 2010, Aug 25. Available from: http://hypertextbook.com/facts/2003/AlexSchlessingerman. shtml

14. Seattle Community Network. Metro risks passenger safety by encouraging standing on the side of their escalators [online]. Accessed 2010 Aug 25. Available from: http://www.scn.org/ bk269/escalators.html

15. Reichert FF, Barros AJ, Domingues MR, Hallal PC. The role of perceived personal barriers to engagement in leisure-time physical activity. Am J Public Health. 2007;(3):515-519.

16. Drewnowski A, Specter SE. Poverty and obesity: the role of energy density and energy costs. Am J Clin Nutr. 2004;79(1):6-16.

\section{Pragmatic and Observational Research}

\section{Publish your work in this journal}

Pragmatic and Observational Research is an international, peer-reviewed, open access journal that publishes data from studies designed to reflect more closely medical interventions in real-world clinical practice compared with classical randomized controlled trials (RCTs). The manuscript

\section{Dovepress}

management system is completely online and includes a very quick and fair peer-review system. 